\title{
Comparison of Misoprostol versus Dinoprostone for delivery induction among pregnant women without concomitant disease
}

\author{
Teresa Gornisiewicz ${ }^{1}$, Katarzyna Kusmierska-Urban²*(i), Hubert Huras² ${ }^{2}$, Aleksander Galas ${ }^{3}$ (1) \\ ${ }^{1}$ Department of Obstetrics and Perinatology, University Hospital, Cracow, Poland \\ ${ }^{2}$ Department of Obstetrics \& Perinatology, Jagiellonian University Medical College, Cracow, Poland \\ ${ }^{3}$ Chair of Epidemiology and Preventive Medicine, Jagiellonian University Medical College, Cracow, Poland \\ *employed until 2019
}

\begin{abstract}
Objectives: Induction of labour is a part of an active prenatal care nowadays and the ideal method of that procedure still remains to be identified. The purpose of this study was to evaluate effectiveness of misoprostol vaginal insert as compared to dinoprostone gel for delivery induction in pregnant women without any comorbidities.

Material and methods: It was a retrospective cohort study of 240 pregnant women. The primary study outcome was successful delivery. Other analysed parameters included time to delivery of a baby, time to the beginning of the first stage of labour, time to vaginal delivery, and duration of all delivery stages. We compared both methods regarding maternal complications during and after delivery. We also reviewed neonatal outcomes such as birth weight, birth length and 1-minute Apgar scores.

Results: The patients' basic characteristics were similar regarding their age, gravidity, parity, height, weight and Bishop score. Time to any delivery and to the onset of a labour in the misoprostol group versus in the dinoprostone group was 14.5 vs $35.6 \mathrm{~h}(\mathrm{p}<0.001)$ and $9.9 \mathrm{~h}$ vs $25.3 \mathrm{~h}(\mathrm{p}<0.001)$ respectively. The chance of the beginning of labour and the baby's delivery over time has been observed to be approximately two times higher for misoprostol as compared to dinoprostone.

Conclusions: Our study showed that using misoprostol vaginal insert in comparison to dinoprostone seems to shorten the time to beginning of the first stage of labour as well as the time to the delivery itself. Some lower Apgar scores observed in the misoprostol group requires further investigation.
\end{abstract}

Key words: misoprostol; dinoprostone; induction of labor

Ginekologia Polska 2020; 91, 12: 726-732

\section{INTRODUCTION}

Finding a safe, quick and effective method of labour induction is a crucial part of a growing need for active prenatal care. Decision on the right moment to complete a pregnancy that would be the best for both the baby and the mother has been always a debatable issue. Modern medicine has developed only a few tools to manage an unfavourable cervix which may be shortly divided into mechanical and pharmacological methods of preinduction. In the final step, induction of delivery involves oxytocin administration which strengthens the uterine contractions leading to childbirth. In current practice, no cervical ripening method appears superior to the others considering their overall effectiveness and safety outcomes [1], which indicates that the ideal method of labour preinduction remains to be identified. Prostaglandins are commonly used in obstet- rics nowadays. Dinoprostone is a natural E2 prostaglandin produced by decidua and amnion, it causes relaxation of cervical collagen and develops uterine fibres contractions [2]. Misoprostol is a synthetic analogue of E1 prostaglandin and, although it was originally registered as a drug in the prevention and treatment of stomach ulcer disease [3], nowadays it is widely used in obstetrics also in preinduction of labour [4].

\section{Objectives}

The purpose of this study was to evaluate effectiveness and safety of misoprostol vaginal insert at a dose of $0.2 \mathrm{mg}$ (Misodel, Ferring Pharmaceuticals Poland sp. z o.o) as compared to dinoprostone gel at a dose of $0.5 \mathrm{mg}$ (Prepidil, Pfizer Polska Sp. z o.o.), administered in daily clinical practice for delivery induction in pregnant women without any comor- 
bidities. Additionally, we evaluated whether mothers' age affected clinical outcomes.

\section{MATERIAL AND METHODS}

It was a retrospective cohort study that included pregnant women requiring labour induction for either medical or obstetric indications, hospitalized at the Obstetric and Perinatology Department at the University Hospital in Cracow between January 2015 and April 2019.

Inclusion criteria were (1) singleton gestation, (2) cephalic foetus presentation, (3) full-term pregnancy, (4) Bishop's score $\leq 4,(5)$ reactive foetal heart rate (FHR) pattern, and (6) lack of spontaneous uterine contractions before administration of the drug.

Patients were excluded for the following reasons: (1) malpresentation, (3) estimated foetal weight $>4500 \mathrm{~g}$ (4) placenta previa or unexplained vaginal bleeding, (5) vasa previa, (6) other known contraindications to vaginal delivery, (7) any contraindication to receiving prostaglandins, (8) previous caesarean delivery or uterine surgery, (9) preterm delivery. Other exclusion criteria included maternal comorbidities such as: hypertension, diabetes mellitus, intrahepatic cholestasis of pregnancy, asthma, and thrombocytopenia.

The primary study outcome was successful vaginal delivery. Other analysed parameters included time from drug administration to vaginal delivery, to any (vaginal or by Caesarean section) delivery, and time to the onset of labour defined as regular uterine contradictions at least every ten minutes with evidence of change in cervical dilatation or cervical effacement, and duration of all delivery stages. We also reviewed neonatal outcomes such as birth weight, birth length and 1-minute Apgar score. Finally, we analysed potential delivery complications like a necessity of emergency Caesarean section, placenta abruption, placenta arrest and a necessity of uterine curettage after vaginal birth, as well as episiotomy and anaemia requiring blood transfusion.

\section{Statistical analysis}

The study group consisted of women who received misoprostol, dinoprostone, and both (after dinoprostone was ineffective the misoprostol was used in some women). Thus, there were three groups of mothers. The first part of the analysis, which is intended to compare successful labour inductions after the implementation of one drug only, presents differences between 'misoprostol only' and 'dinoproston only' groups. In order to compare basic characteristics of the study groups for interval scale variables [age, time, weight, body mass index (BMI)], first normal distribution in groups was assessed by Shapiro-Wilk test, and then for normally distributed variables the t-test for equal or unequal variances, and for skewed variables the U-Mann-Whitney test were used to assess significance. Chi-squared Person's test was used for nominal or ordinal scale variables provided that the expected value of at least five was observed in each cell, otherwise the exact Fisher's test was performed. As a next step, to reveal whether there is a difference in the effectiveness between implemented drugs an intention to treat (ITT) approach was implemented - meaning mothers started with misoprostol were considered as the first group, and mothers started with dinoproston as the second group irrespective of whether the mother was given later the other drug for induction purposes or not. The proportional Cox regression model was performed to assess the strength of difference between misoprostol and dinoprostone in the effectiveness of delivery upon time. The calculated hazard ratio shows how many times the delivery is more or less likely in a specified amount of time. Models were created as both unadjusted and adjusted for the clinically important covariates. In addition, it was tested a possible impact of woman's age on the efficacy of the treatment. For that purpose, firstly, a linear regression of the mother's age on the time between drug implementation and the beginning of labour or the delivery of a baby, and additionally the second stage of labour, with the treatment type covariate were performed. Secondly, to check whether the difference between misoprostol and dinoprostone depended on mother's age (the test for a modification effect of the mother's age $<35$, and 35+) the interaction terms between categorised mother's age and a group type variable in the ANOVA models were used. All the analyses were done using the IBM SPSS Statistics version 25. Pairwise procedure was used for missing data. Results (differences) were considered statistically significant if the $p$-value was less than 0.05 .

\section{RESULTS}

There were 560 pregnant women identified in medical records as admitted to the Obstetric and Perinatology Department at the University Hospital in Cracow, Poland for induction of delivery in the period from January 2015 till April 2019. Out of 560, 320 were excluded due to the presence of any of the co-morbidity mentioned under the exclusion criteria. In the remaining 240 women there were 93 women who received misoprostol and 147 who were given dinoprostone. In the last-mentioned group, however, there were 39 (26.5\%) which were observed as not-reacting to the drug, and they received after some time misoprostol additionally. Thus "one drug successful labour induction" groups included 201 pregnant women, out of whom 93 (46.3\%) were treated with misoprostol and 108 (53.7\%) were given dinoprostone.

The basic characteristics of mothers were similar across study groups regarding their age, gravidity, parity, weight, and BMI at admission. There were no statistically significant differences in pre-ripening cervical characteristics either, or the initial Bishop score in all patients was $\leq 4$ (Tab. 1). Consid- 
Table 1. Clinical characteristics of the study groups (across "after one drug successful delivery" groups)

\begin{tabular}{|c|c|c|c|}
\hline & Misoprostol [n = 93] & Dinoprostone $[n=108]$ & Significance \\
\hline $\begin{array}{l}\text { Maternal age [years] } \\
\text { Mean, (SD) } \\
\text { Median (Q1-Q3) }\end{array}$ & $\begin{array}{l}31.1(4.4)^{*} \\
31.0(28.5-34.0)\end{array}$ & $\begin{array}{l}30.6(4.9) \\
30.0(28.0-34.0)\end{array}$ & $\mathrm{pMW}=0.293$ \\
\hline $\begin{array}{l}\text { Weight at admission [kg] } \\
\text { Mean, (SD) } \\
\text { Median (Q1-Q3) }\end{array}$ & $\begin{array}{l}{[n=47]^{*}} \\
76.8(10.9) \\
75.0(69.0-83.0)\end{array}$ & $\begin{array}{l}{[n=63]} \\
78.8(13.1) \\
77.0(70.0-86.0)\end{array}$ & $\mathrm{PMW}^{\mathrm{MW}}=0.385$ \\
\hline $\begin{array}{l}\text { Height }[\mathrm{cm}] \\
\text { Mean, (SD) } \\
\text { Median (Q1-Q3) }\end{array}$ & $\begin{array}{l}{[n=84]} \\
165.7(5.7) \\
166.5(162.0-170.0)\end{array}$ & $\begin{array}{l}{[n=97]} \\
167.3(5.9) \\
168.0(164.0-171.0)\end{array}$ & $\mathrm{Pt}^{\mathrm{t}-\mathrm{e}}=0.054$ \\
\hline $\begin{array}{l}\text { Body mass index at admission }\left[\mathrm{kg} / \mathrm{m}^{2}\right] \\
\text { Mean, (SD) } \\
\text { Median (Q1-Q3) }\end{array}$ & $\begin{array}{l}{[n=46]} \\
28.5(3.7)^{*} \\
27.4(25.9-30.4)\end{array}$ & $\begin{array}{l}{[n=63]} \\
27.9(4.3) \\
27.1(24.8-30.1)\end{array}$ & $\mathrm{P}^{\mathrm{MW}}=0.406$ \\
\hline Number of pregnancies [n, (\%)] & & & $\begin{array}{l}\mathrm{df}=2 \\
\mathrm{pchi2}^{\mathrm{ch}}=0.713\end{array}$ \\
\hline 1 & $52(55.9 \%)$ & $66(61.1 \%)$ & \\
\hline 2 & $20(21.5 \%)$ & $22(20.4 \%)$ & \\
\hline$\geq 3$ & $21(22.6 \%)$ & $20(18.5 \%)$ & \\
\hline $\begin{array}{l}\text { Parity history (current delivery included) } \\
\text { [n (\%)] }\end{array}$ & & & $\begin{array}{l}\mathrm{df}=2 \\
\text { pchi2 }=0.854\end{array}$ \\
\hline 1 & $64(68.8 \%)$ & $77(71.3 \%)$ & \\
\hline 2 & $18(19.4 \%)$ & $21(19.4 \%)$ & \\
\hline 3 & $11(11.8 \%)$ & $10(9.3 \%)$ & \\
\hline Nulliparous [n, (\%)] & $62(66.7 \%)$ & $76(70.4 \%)$ & $\begin{array}{l}\mathrm{df}=1 \\
\text { pchi2 }=0.648\end{array}$ \\
\hline Miscarriage history [n, (\%)] & & & $\begin{array}{l}\mathrm{df}=1 \\
\text { pchi2 }=0.305\end{array}$ \\
\hline No & $70(75.3 \%)$ & $88(81.5 \%)$ & \\
\hline Yes & $23(24.7 \%)$ & $20(18.5 \%)$ & \\
\hline \multicolumn{4}{|l|}{ Pre-ripening cervical characteristics [n (\%)] } \\
\hline Dilatation $\leq 1 \mathrm{~cm}$ & $86(92.5 \%)$ & $99(91.7 \%)$ & $\begin{array}{l}\mathrm{df}=1 \\
\mathrm{pchi2}=0.999\end{array}$ \\
\hline Effacement $\leq 50 \%$ & $85(91.4 \%)$ & $101(93.5 \%)$ & $\begin{array}{l}\mathrm{df}=1 \\
\text { pchi2 }^{\text {che }} 0.600\end{array}$ \\
\hline $\begin{array}{l}\text { Gestational age [weeks] }]^{\#} \\
\text { Mean, (SD) } \\
\text { Median (Q1-Q3) }\end{array}$ & $\begin{array}{l}39.7(1.8)^{*} \\
40.6(38.9-40.9)\end{array}$ & $\begin{array}{l}40.6(0.7)^{*} \\
40.9(40.5-41.0)\end{array}$ & $\mathrm{PMW}^{\mathrm{MW}}<0.001$ \\
\hline $\begin{array}{l}\text { Estimated birth weight [g] } \\
\text { Mean, (SD) } \\
\text { Median (Q1-Q3) }\end{array}$ & $\begin{array}{l}{[n=54]} \\
3325(552)^{*} \\
3450(3000-3748)\end{array}$ & $\begin{array}{l}{[n=37]} \\
3588(413) \\
3682(3233-3883)\end{array}$ & $\mathrm{P}^{\mathrm{MW}}=0.027$ \\
\hline
\end{tabular}

${ }^{*} \mathrm{p}<0.05$ by the Shapiro-Wilk test for normal distribution; "at a time of administration of the first dose of the drug; MW - the U-Mann-Whitney test; $t$-e - the Student's $\mathrm{t}$-test for equal variances; chi2 - the chi-squared test, $\mathrm{df}$ - degrees of freedom; $\mathrm{F}$ - the exact Fisher's test

ering gestational age, it was slightly lower in the misoprostol group as compared to dinoprostone group (medians: $40.6 \mathrm{vs}$ 40.9 weeks respectively, $\mathrm{p}<0.001$ ), additionally, estimated birth weight was also lower in the misoprostol group (medians: 3450 vs $3682 \mathrm{~g}$, respectively, $\mathrm{p}=0.027$ ). The indications for labour induction did not differ significantly between the two groups, although Rh incompatibility was observed slightly more frequently in the dinoprostone group $(4.1 \%$ vs $1.1 \%$ ) and foetal indications (including foetal growth restriction) were noticed more frequently in the misoprostol group (16.1\% vs $8.2 \%)$. Most inductions were initiated due to prolonged pregnancy exceeding the term date. There was no operative vaginal delivery.

The proportion of mothers who underwent vaginal delivery was comparable between the groups, as it was $68.8 \%$ in the misoprostol and $76.9 \%$ in the dinoprostone group $(p=0.207)$. There were also no differences between the rate of Caesarean section or indications for such delivery between the two groups. The most often causes of Caesarean section were foetal distress seen in cardiotocography 
Table 2. Mode of delivery and indications for caesarean section across "after one drug successful delivery" groups

\begin{tabular}{|l|l|l|l|}
\hline & Misoprostol [n= 93] & Dinoprostone $[\mathbf{n = 1 0 8 ]}$ & Significance \\
\hline Cesarean section & $29(31.2 \%)$ & $25(23.1 \%)$ & $\begin{array}{l}\mathrm{df}=1 \\
\mathrm{pchi2}=0.207\end{array}$ \\
\hline $\begin{array}{l}\text { Emergency Caesarean delivery out of } \\
\text { total deliveries }\end{array}$ & $19(20.4 \%)$ & $10(9.3 \%)$ & $\begin{array}{l}\mathrm{df}=1 \\
\mathrm{pchi2}=0.028\end{array}$ \\
\hline $\begin{array}{l}\text { Emergency Caesarean delivery out of } \\
\text { total Caesarean sections }\end{array}$ & $\begin{array}{l}{[n=29]} \\
19[65.5 \%]\end{array}$ & $\begin{array}{l}{[\mathrm{n}=25]} \\
10[40.0 \%]\end{array}$ & $\begin{array}{l}\mathrm{df}=1 \\
\mathrm{pchi2}=0.100\end{array}$ \\
\hline $\begin{array}{l}\text { Vaginal delivery } \\
\text { Indications for Caesarean section }\end{array}$ & $64(68.8 \%)$ & $83(76.9 \%)$ & $\begin{array}{l}\mathrm{df}=1 \\
\mathrm{pchi2}=0.207\end{array}$ \\
\hline Foetal distress & {$[\mathrm{n}=29]$} & {$[\mathrm{n}=25]$} & $\mathrm{p}=0.207$ \\
\hline $\begin{array}{l}\text { Labor arrest during first stage (First-stage } \\
\text { Caesarean) }\end{array}$ & $18(62.1 \%)$ & $10(40.0 \%)$ & \\
\hline $\begin{array}{l}\text { Labor arrest during second stage } \\
\text { (Second-stage Caesarean) }\end{array}$ & $4(20.7 \%)$ & $10(40.0 \%)$ & \\
\hline Fetal hand prolapse & $1(3.4 \%)$ & $5(20.0 \%)$ & \\
\hline
\end{tabular}

chi $^{2}-$ the chi-squared test; $\mathrm{df}-$ degrees of freedom; $\mathrm{F}-$ the exact Fisher's test

Table 3. Postpartum complications among study participants

\begin{tabular}{|c|c|c|c|c|}
\hline & Misoprostol [ $n=93]$ & Dinoprostone $[n=108]$ & Dinoprostone + misoprostol $[n=39]$ & Significance \\
\hline Any complication & $14(15.1 \%)$ & $12(11.1 \%)$ & $9(23.1 \%)$ & $\begin{array}{l}\mathrm{df}=2 \\
\mathrm{p}^{\mathrm{chi2}}=0.196\end{array}$ \\
\hline Blood transfusion & $2(2.2 \%)$ & $2(1.9 \%)$ & $2(5.1 \%)$ & $P F=0.470$ \\
\hline Uterine hyper-stimulation & $2(2.2 \%)$ & 0 & $2(5.1 \%)$ & $P F=0.059$ \\
\hline Curettage after delivery & $8(8.6 \%)$ & $9(8.3 \%)$ & $3(7.7 \%)$ & $\mathrm{PF}=0.999$ \\
\hline Episiotomy & $26(28.0 \%)$ & $42(38.9 \%)$ & $17(43.6 \%)$ & $\begin{array}{l}\mathrm{df}=1 \\
\text { pchi2 }=0.137\end{array}$ \\
\hline Rupture of perineum (any type) & $15(16.1 \%)$ & $24(22.2 \%)$ & $4(10.3 \%)$ & $\begin{array}{l}\mathrm{df}=1 \\
\mathrm{pchi2}^{\mathrm{c}}=0.224\end{array}$ \\
\hline $\begin{array}{l}\text { Rupture of perineum } \\
\text { No rupture } \\
\text { I-stage } \\
\text { II-stage } \\
\text { III-stage }\end{array}$ & $\begin{array}{l}78(83.9 \%) \\
14(15.1 \%) \\
1(1.1 \%) \\
0\end{array}$ & $\begin{array}{l}84(77.8 \%) \\
20(18.5 \%) \\
2(1.9 \%) \\
2(1.9 \%)\end{array}$ & $\begin{array}{l}35(89.7 \%) \\
3(7.7 \%) \\
0 \\
1(2.6 \%)\end{array}$ & $\mathrm{PF}=0.427$ \\
\hline
\end{tabular}

$\mathrm{chi}^{2}$ - the chi-squared test; $\mathrm{df}$ - degrees of freedom; $\mathrm{F}$ - the exact Fisher's test

tracing or lack of the labour progress, although there was significantly more often emergency Caesarean delivery out of all deliveries $(p=0.028)$ in the misoprostol group (Tab. 2). For the analysis of the safety, the three groups, i.e., misoprostol, dinoprostone and dinoprostone followed by misoprostol were considered. Delivery complications were categorized into the following: anaemia with blood transfusion need, uterine hyperstimulation, uterus curettage after delivery, shoulder dystocia or the perineum rupture needing surgical suturing. There were no significant differences in postpartum complications between groups (Tab. 3).

The oxytocin usage to accelerate the contraction activity of the uterine muscle was necessary in eight patients (8.6\%) from the misoprostol group, and in 55 patients (37.4\%) from dinoprostone group, which reached a statistically significant difference $(p<0.001)$.

The misoprostol use appeared to significantly shorten the time to any delivery compared to dinoprostone gel (medians: 14.5 vs $35.6 \mathrm{~h}, \mathrm{p}<0.001$ ), it also shortened the time to beginning of delivery and vaginal delivery. There were no significant differences found in duration of any stage of labour between the two groups (Tab. 4).

There were statistically significant differences in Apgar scores of the baby (Tab. 5). The birth weight and length were statistically different, which may reflect the previously noted difference in gestational age at the delivery (Tab. 1 and 5).

As a next step, we checked whether woman's age had been associated with the analyzed time periods. After the 
Table 4. Time intervals to delivery intention to treat groups

\begin{tabular}{|c|c|c|c|}
\hline & $\begin{array}{l}\text { Misoprostol first } \\
{[n=93]}\end{array}$ & $\begin{array}{l}\text { Dinoprostone first } \\
{[n=147]}\end{array}$ & Significance \\
\hline $\begin{array}{l}\text { Time admission to delivery (vaginal or Caesarean section) [h] } \\
\text { Mean, (SD) } \\
\text { Median (Q1-Q3) }\end{array}$ & $\begin{array}{l}47.0(69.3)^{*} \\
25.8(14.0-44.0)\end{array}$ & $\begin{array}{l}67.3(73.0)^{*} \\
51.2(31.3-81.3)\end{array}$ & $\mathrm{PMW}^{\mathrm{MW}}<0.001$ \\
\hline $\begin{array}{l}\text { Time drug application to delivery (vaginal or Caesarean section) [h] } \\
\text { Mean, (SD) } \\
\text { Median (Q1-Q3) }\end{array}$ & $\begin{array}{l}14.5(13.8)^{*} \\
11.0(8.0-17.4)\end{array}$ & $\begin{array}{l}35.6(25.0)^{*} \\
28.8(13.5-51.9)\end{array}$ & $\mathrm{PMW}^{\mathrm{MW}}<0.001$ \\
\hline $\begin{array}{l}\text { Time drug application to vaginal delivery (Caesarean sections excluded) [h] } \\
\text { Mean, (SD) } \\
\text { Median (Q1-Q3) }\end{array}$ & $\begin{array}{l}{[n=64]} \\
15.1(15.6)^{*} \\
11.0(8.7-17.8)\end{array}$ & $\begin{array}{l}{[n=107]} \\
31.3(24.4)^{*} \\
26.0(12.0-47.2)\end{array}$ & $\mathrm{PMW}^{\mathrm{MW}}<0.001$ \\
\hline $\begin{array}{l}\text { Time drug application to the beginning of a labor [h] } \\
\text { Mean, (SD) } \\
\text { Median (Q1-Q3) }\end{array}$ & $\begin{array}{l}{[n=68]} \\
9.9(15.0)^{*} \\
6.2(3.9-11.5)\end{array}$ & $\begin{array}{l}{[n=115]} \\
25.3(23.0)^{*} \\
20.9(5.8-40.8)\end{array}$ & $\mathrm{PMW}^{\mathrm{M}}<0.001$ \\
\hline $\begin{array}{l}\text { I stage of labor duration }[\mathrm{h}] \\
\text { Mean, (SD) } \\
\text { Median (Q1-Q3) }\end{array}$ & $\begin{array}{l}{[n=68]} \\
4.8(2.2)^{*} \\
4.8(3.0-6.0)\end{array}$ & $\begin{array}{l}{[n=115]} \\
5.4(2.7)^{*} \\
5.0(3.0-7.0)\end{array}$ & $\mathrm{PMW}=0.181$ \\
\hline $\begin{array}{l}\text { Il stage of labor duration [min] } \\
\text { Mean, (SD) } \\
\text { Median (Q1-Q3) }\end{array}$ & $\begin{array}{l}{[n=68]} \\
30.0(28.6)^{*} \\
20.0(10.0-40.0)\end{array}$ & $\begin{array}{l}{[n=111]} \\
37.7(33.4)^{*} \\
30.0(15.0-60.0)\end{array}$ & $\mathrm{pMW}=0.058$ \\
\hline $\begin{array}{l}\text { III stage of labor duration [min] } \\
\text { Mean, (SD) } \\
\text { Median (Q1-Q3) }\end{array}$ & $\begin{array}{l}{[n=63]} \\
8.8(5.6)^{*} \\
10.0(5.0-10.0)\end{array}$ & $\begin{array}{l}{[n=106]} \\
8.6(4.2)^{*} \\
10.0(5.0-10.0)\end{array}$ & $\mathrm{p}^{\mathrm{MW}}=0.771$ \\
\hline
\end{tabular}

${ }^{*} \mathrm{p}<0.05$ by the Shapiro-Wilk test for normal distribution; $\mathrm{MW}$ - the U-Mann-Whitney test

Table 5. Neonatal outcomes across intention to treat misoprostol and dinoprostone groups

\begin{tabular}{|c|c|c|c|}
\hline & Misoprostol first [ $n=93$ ] & Dinoprostone first $[n=147]$ & Significance \\
\hline $\begin{array}{l}\text { Apgar score [points] } \\
\text { Mean, (SD) } \\
\text { Median (Q1-Q3) }\end{array}$ & $\begin{array}{l}9.4(1.6)^{*} \\
10.0(10.0-10.0)\end{array}$ & $\begin{array}{l}9.8(0.6)^{*} \\
10.0(10.0-10.0)\end{array}$ & $\mathrm{PMW}=0.041$ \\
\hline $\begin{array}{l}\text { Apgar score } \leq 6 \text { points at the } 1 s t \min (n, \%) \\
\text { Apgar score } 7-8 \text { points at the } 1 \text { st } \min (n, \%) \\
\text { Apgar score } 9-10 \text { points at the } 1 \text { st } \min (n, \%)\end{array}$ & $\begin{array}{l}8(8.6 \%) \\
4(4.3 \%) \\
81(87.1 \%)\end{array}$ & $\begin{array}{l}2(1.4 \%) \\
4(2.7 \%) \\
141(95.9 \%)\end{array}$ & $p^{F}=0.018$ \\
\hline $\begin{array}{l}\text { Birth weight [g] } \\
\text { Mean, (SD) } \\
\text { Median (Q1-Q3) }\end{array}$ & $\begin{array}{l}{[n=93]} \\
3385(530) \\
3420(3045-3750)\end{array}$ & $\begin{array}{l}{[n=146]} \\
3623(417) \\
3625(3320-3955)\end{array}$ & $\mathrm{p}^{\mathrm{t}-\mathrm{ue}}<0.001$ \\
\hline $\begin{array}{l}\text { Birth length }[\mathrm{cm}] \\
\text { Mean, (SD) } \\
\text { Median (Q1-Q3) }\end{array}$ & $\begin{array}{l}{[n=93]} \\
54.9(3.4) \\
55.0(53.0-57.0)\end{array}$ & $\begin{array}{l}{[n=146]} \\
56.0(3.0)^{*} \\
56.0(54.0-58.0)\end{array}$ & $\mathrm{p}^{\mathrm{MW}}=0.008$ \\
\hline Female $[n, \%]$ & $44(47.3 \%)$ & $68(46.3 \%)$ & $\begin{array}{l}d f=1 \\
p^{\text {chi2 }}=0.895\end{array}$ \\
\hline
\end{tabular}

${ }^{*} \mathrm{p}<0.05$ by the Shapiro-Wilk test for normal distribution; MW - the U-Mann-Whitney test; $t$-ue - the Student's t-test for unequal variances

woman's age was regressed on the time from the drug implementation to the beginning of a labour (to the first stage of labour), to the delivery of a baby (to the end of second stage of labour) and additionally on the duration of the second stage of a labour only, no one result was statistically significant ( $p$ values: $0.114 ; 0.308 ; 0.131$, respectively). Additionally, when the differences in the considered time periods between drug types were analysed with interaction terms between woman's age categorical variable no result had been significant either ( $p$ values: $0.970 ; 0.757 ; 0.800$ ).
Finally, Cox regression models were performed to assess whether there were differences between misoprostol and dinoprostone upon time in the labour induction. The results showed that misoprostol increased more than twice the chance of beginning the labour or delivery of a baby in comparison to dinoprostone. Even after adjustment for the covariates which might influence the process, like mother's age, number of pregnancies, cervical state, and oxytocin use, the probability still was significantly higher (Tab. 6 and 7). 
Table 6. The relative probability (assessed by the hazard ratio) for induction of a labor for misoprostol compared to dinoprostone

\begin{tabular}{|c|c|c|c|}
\hline & Hazard ratio & $95 \% \mathrm{Cl}$ & p value \\
\hline Beginning of labor & 2.57 & $1.85-3.57$ & $p<0.001$ \\
\hline Beginning of labor ${ }^{1}$ & 2.44 & $1.75-3.40$ & $p<0.001$ \\
\hline Beginning of labor ${ }^{2}$ & 2.42 & $1.73-3.39$ & $p<0.001$ \\
\hline Beginning of labor ${ }^{3}$ & 2.10 & $1.49-2.97$ & $p<0.001$ \\
\hline
\end{tabular}

The proportional Cox regression model; ${ }^{1}$ Adjusted for number of pregnancies, mother's age; ${ }^{2}$ Adjusted for the covariates as in (1) and additionally for cervical effacement; ${ }^{3}$ Adjusted for the covariates as in (2) and additionally for oxytocin use; $\mathrm{Cl}$ - confidence interval

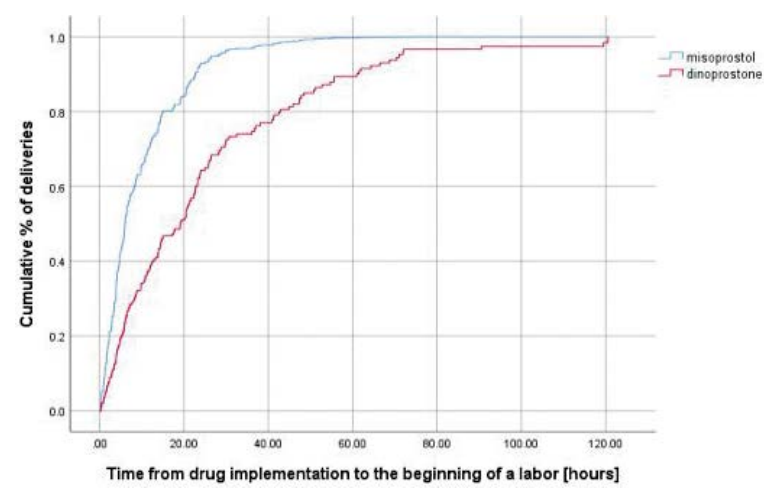

Figure 1. Cox regression model - from drug implementation to the beginning of labor

\section{DISCUSSION}

The use of pharmaceutical induction of labour increased in many European countries during the last decades, for example in Norway the rate increased from $12.5 \%$ in 2003 to $20.3 \%$ in 2013 . The rate of caesarean section in the induced patients' group did not change, and it remained stable at 17.1 and $17.4 \%$, respectively [5]. It might be connected with introducing into the contemporary obstetrics the use of prostaglandins, which facilitate cervical ripening and accelerate uterine contractions like in the natural course of delivery.

The purpose of this study was a comparison of two prostaglandins used in everyday clinical practice, which are, among others, recommended by the Polish Society of Gynaecologists and Obstetricians Guidelines for labour induction [6]. We verified that vaginally implemented misoprostol insert was more effective than the dinoprostone gel in induction of labour in pregnant women without any comorbidities at term. Our findings are in line with the results of Sharp et al. [7] who demonstrated a statistically shorter time to the delivery when using misoprostol vaginal insert rather than dinoprostone vaginal gel, namely means 18.2 h (11.6-27.6) vs 21.8 h (19.0-23.9), respectively. In our study, the mean interval between the implementation of misoprostol to the time of delivery was even shorter (14.5 h). We have shown that misoprostol, in
Table 7. The relative probability (assessed by the hazard ratio) for baby's delivery for misoprostol as compared to dinoprostone

\begin{tabular}{|l|l|l|l|}
\hline & Hazard ratio & $\mathbf{9 5 \%} \mathrm{Cl}$ & p value \\
\hline Baby's delivery & 3.21 & $2.40-4.29$ & $\mathrm{p}<0.001$ \\
\hline Baby's delivery & 3.07 & $2.28-4.13$ & $\mathrm{p}<0.001$ \\
\hline Baby's delivery $^{2}$ & 3.09 & $2.29-4.16$ & $\mathrm{p}<0.001$ \\
\hline Baby's delivery $^{3}$ & 2.59 & $1.90-3.53$ & $\mathrm{p}<0.001$ \\
\hline
\end{tabular}

The proportional Cox regression model; ${ }^{1}$ Adjusted for number of pregnancies, mother's age; ${ }^{2}$ Adjusted for the covariates as in (1) and additionally for cervical effacement; ${ }^{3}$ Adjusted for the covariates as in (2) and additionally for oxytocin use; $\mathrm{Cl}$ - confidence interval

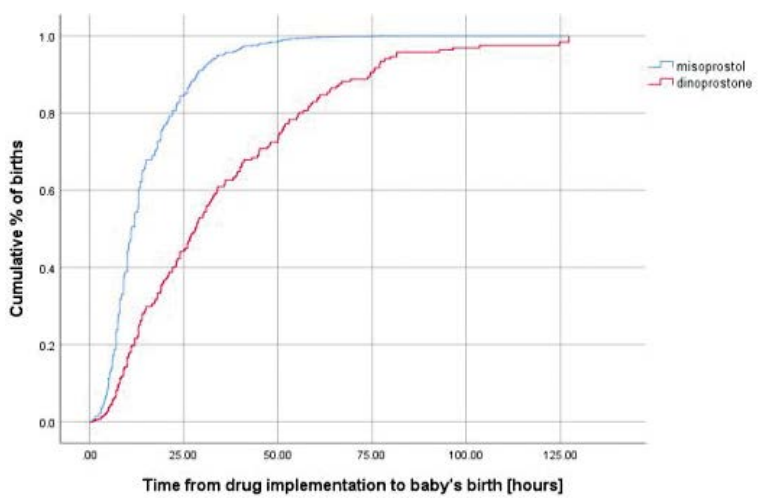

Figure 2. Cox regression model - from drug implementation to baby's delivery

comparison to dinoprostone, resulted in twice higher chance of successful beginning of delivery regardless the number of previous pregnancies, gestational age or cervical state. Even if additionally, oxytocin use or mother's age were considered, the chance of labour initiation across time was still 1.9 times higher in this group (Tab. 6, Fig. 1). We observed similar effects on the time to baby's delivery (Tab. 7, Fig. 2). Those results indicated that misoprostol was more effective than dinoprostone in the induction of labour, which also further supported the findings of the other studies [8-9,12]. It is worth mentioning that most of available studies are based on different routes of administration of misoprostol (oral tablets, tablets implemented into the posterior vaginal fornix, vaginal insert) or dinoproston (vaginal insert, vaginal gel), which may interrupt the direct comparison between result and conclusions of those studies. One study which compared misoprostol vaginal insert (MVI) and misoprostol vaginal tablets (MVT) for induction of labour in term pregnancies [10] showed that MVI achieved a more vaginal delivery rate within 24-hours and shorter time from induction to vaginal delivery than MVT, with no influence on caesarean section rate, postpartum haemorrhage, Apgar score below 7. Remarkably similar conclusions were made after comparing of the misoprostol vaginal insert with oral misoprostol tablets in favour of vaginal rout [11]. 
The results of our study suggested that use of misoprostol vaginal insert shorten the time intervals from medicament implementation to active labour and to delivery itself when compared with preinduction with dinoprostone.

Incidence of vaginal deliveries after induction of labour vary widely in the literature; it was $92.5 \%$ [7], 88\% [12], 73.3\% [8] in the misoprostol group, compared with dinoprostone $89,1 \%, 74 \%, 71,6 \%$ respectively. In our study, the misoprostol intervention ended in the vaginal delivery in $68.8 \%$ cases in comparison to $76.9 \%$ in the dinoprostone group.

We observed lower mean birth weight of the neonates in the misoprostol group, which we assumed that was mostly connected with the lower gestational age in this group ( 40.6 vs $40.9 p<0.001$ ). However, we believe that it had no influence on the effectiveness of misoprostol, since there was another study where the misoprostol group had higher mean birth weight and gestational age compared to the dinoprostone group and the time interval to delivery was still shorter [12] or in another one in which the time from drug application to onset of labour was also significantly reduced [13].

As the prostaglandins'administration may result in many adverse outcomes, in both the mother and the infant, we analysed the results thoroughly. In both groups we have noticed disturbances in the foetal heart rate pattern described as foetal distress needing emergency caesarean delivery, with no statistical difference. In the end of our observation, we have shown that the caesarean delivery rates and its indications, as well as the maternal complications were not significantly different between studied groups.

In our study the analysis of the factors that potentially might have influenced the effect of each intervention showed no differences between the groups regarding maternal age, parity, prior vaginal delivery, miscarriage history, patients' body mass index, Bishop's scale score before the drug administration or estimated foetal weight.

There were a few limitations of this work that should be acknowledged. First, the study was retrospective and the enrolment of subjects for this study was not randomised. Additionally, we reviewed medical records as the source of information, and there were several missing data which were not possible to retrieve. Moreover, our sample size was limited; however, it was big enough to reach statistical significance for some of our results. It was not observed in our study any significant difference in the complication rate between different drugs, but, in our opinion, it should be confirmed on large sample size study. Thus, further studies on bigger groups are still needed.

\section{CONCLUSIONS}

Our study showed that using the misoprostol vaginal insert in comparison to dinoprostone gel seems to increase the chance of delivery and to shorten the time to beginning of the first stage of labour as well as the time to the delivery itself regardless the way, vaginal birth or caesarean section with no influence on maternal complications. Some lower Apgar scores observed in the misoprostol group requires further investigation.

\section{Acknowledgments}

Not applicable.

\section{Conflict of interest}

The authors declare no conflict of interest.

\section{Financial disclosure}

The authors receive no financial support for the study conduct.

\section{REFERENCES}

1. Blanc-Petitjean P, Carbonne B, Deneux-Tharaux C, et al. MEDIP study group. Comparison of effectiveness and safety of cervical ripening methods for induction of labour: A population-based study using coarsened exact matching. Paediatr Perinat Epidemiol. 2019; 33(5): 313-322, doi: 10.1111/ppe.12569, indexed in Pubmed: 31342567.

2. Induction of Labour. Society of Obstetricians and Gynaecologist of Canada Clinical Practise Guideline No 296. J Obstet and Gynecol Canada. 2013; 35: s1-s18.

3. Huras H, Radoń-Pokracka M, Górnisiewicz T. Indukcja porodu w świetle aktualnego piśmiennictwa. Ginekol Położ. 2016; 11(1): 21-25.

4. Leszczyńska-Gorzelak B, Laskowska M, Oleszczuk J. Comparative analysis of the effectiveness of misoprostol and prostaglandin $E(2)$ in the preinduction and induction of labor. Med Sci Monit. 2001; 7(5): 1023-1028, indexed in Pubmed: 11535953.

5. Dögl M, Vanky E, Heimstad R. Changes in induction methods have not influenced cesarean section rates among women with induced labor. Acta Obstet Gynecol Scand. 2016; 95(1): 112-115, doi: 10.1111/aogs.12809, indexed in Pubmed: 26489875.

6. Bomba-Opoń D, Drews K, Huras H, et al. Indukcja porodu — algorytmy kliniczne. Wytyczne Polskiego Towarzystwa Ginekologów i Położników. Ginekologia i Perinatologia Praktyczna. 2018; 3(1): 23-29.

7. Sharp A, Faluyi D, Alfirevic Z. Misoprostol vaginal insert (Mysodelle) versus Dinoprostone intravaginal gel (Prostin) for induction of labour. Eur J Obstet Gynecol Reprod Biol. 2019; 240: 41-44, doi: 10.1016/j. ejogrb.2019.06.010, indexed in Pubmed: 31226576.

8. Wing DA, Brown R, Plante LA, et al. Misoprostol vaginal insert and time to vaginal delivery: a randomized controlled trial. Obstet Gynecol. 2013; 122(2 Pt 1): 201-209, doi: 10.1097/AOG.0b013e31829a2dd6, indexed in Pubmed: 23857539.

9. Górnisiewicz T, Jaworowski A, Zembala-Szczerba M, et al. Analysis of intravaginal misoprostol $0.2 \mathrm{mg}$ versus intracervical dinoprostone $0.5 \mathrm{mg}$ doses for labor induction at term pregnancies. Ginekol Pol. 2017; 88(6): 320-324, doi: 10.5603/GP.a2017.0060, indexed in Pubmed: 28727132.

10. Bolla D, Weissleder SV, Radan AP, et al. Misoprostol vaginal insert versus misoprostol vaginal tablets for the induction of labour: a cohort study. BMC Pregnancy Childbirth. 2018; 18(1): 149, doi: 10.1186/s12884-0181788-z, indexed in Pubmed: 29747591.

11. Eriksson A, Jeppesen S, Krebs L. Induction of labour in nulliparous women- quick or slow: a cohort study comparing slow-release vaginal insert with low-dose misoprostol oral tablets. BMC Pregnancy Childbirth. 2020; 20(1): 79, doi: 10.1186/s12884-020-2770-0, indexed in Pubmed: 32033600.

12. Maggi C, Mazzoni G, Gerosa V, et al. Labor induction with misoprostol vaginal insert compared with dinoprostone vaginal insert. Acta Obstet Gynecol Scand. 2019; 98(10): 1268-1273, doi: 10.1111/aogs.13667, indexed in Pubmed: 31140585.

13. Mayer RB, Oppelt P, Shebl O, et al. Initial clinical experience with a misoprostol vaginal insert in comparison with a dinoprostone insert for inducing labor. Eur J Obstet Gynecol Reprod Biol. 2016; 200: 89-93, doi: 10.1016/j.ejogrb.2016.03.008, indexed in Pubmed: 26995147. 